\title{
Effect of Nitrogen and Phosphorus Starvations on Chlorella vulgaris Lipids Productivity and Quality under Different Trophic Regimens for Biodiesel Production
}

\author{
Gianluca Belotti, Marco Bravi, Benedetta de Caprariis, Paolo de Filippis, Marco Scarsella*
}

Department of Chemical Engineering, Sapienza University of Rome, Via Eudossiana, Rome, Italy.

Email: *marco.scarsella@uniroma1.it

Received November $19^{\text {th }}, 2013$; revised December $2^{\text {nd }}, 2013$; accepted December $10^{\text {th }}, 2013$

Copyright (C) 2013 Gianluca Belotti et al. This is an open access article distributed under the Creative Commons Attribution License, which permits unrestricted use, distribution, and reproduction in any medium, provided the original work is properly cited.

\begin{abstract}
In this work the effects of nutrients starvations on Chlorella vulgaris were investigated in different trophic regimens. For all the tested conditions, the cellular response to nutrient starvation and trophic regimen was evaluated on specific growth rate, biomass and lipids productivity, lipids content and quality. These parameters are all crucial for microalgae biodiesel production, but in literature the lipids quality, in terms of polar and nonpolar lipids, is often neglected. Thus the typical high content of polar lipids, a class of molecules that negatively affects the biodiesel production process, of microalgae crude oil is generally not analyzed. In the tested conditions the triggering effect of nitrogen starvation on total lipids productivity is confirmed only in autotrophic regimen, while in mixotrophic and heterotrophic conditions the total lipids productivity is reduced, as a consequence of the lowered biomass productivity, but with an evident compositional shift towards nonpolar lipids production (from $0.5 \mathrm{mg} / \mathrm{Ld}$ to $41.6 \mathrm{mg} / \mathrm{Ld}$ in mixotrophic regimen). Nitrogen and phosphorus co-starvation induced the highest nonpolar lipids productivity in all trophic regimens. Maximum nonpolar lipids productivity was obtained in nitrogen limited and phosphorus deprived condition during mixotrophic growth, equal to $118.2 \mathrm{mg} / \mathrm{Ld}$, representing the $80 \%$ of produced lipids. On the basis of the obtained results, the possibility of a short pre-harvesting cultural step to maximize the nonpolar lipids yield of the crop could be envisaged.
\end{abstract}

Keywords: Biodiesel; Chlorella Vulgaris; Trophic Regimens; Nutrients Starvation; Nonpolar Lipids Productivity

\section{Introduction}

Among third generation biofuels, those derived from microalgae are emerging at the forefront of the relevant research domain $[1,2]$. Microalgae derived biodiesel is, in fact, considered one of the most technically feasible alternative to fossil fuels and virtually does not present the major drawbacks associated with first and second generation biofuels. Oleaginous unicellular algae, could have an enormous potential as energetic crop for biodiesel production, besides for their high lipids content, also for their short and season independent life-cycle, high growing rate and no need for agrochemicals. Finally, microalgae cultivation does not compete for fertile fields with food crops [3-9].

Although the lipid-producing capability of microalgae is genetically controlled, their quantity and quality is strictly related to the growing condition and culturing

${ }^{*}$ Corresponding author. parameters, including water quality, $\mathrm{pH}$, carbon dioxide concentration, nutrients deficit, light intensity, and temperature. Extensive literature exists on the manipulation of the algal lipid metabolism by means of specific growing conditions, reaching significant levels of lipids content, nevertheless qualitative algal lipids composition has been often overlooked in the past [8,10-14].

Indeed any lipid raw materials suitable for biodiesel production should be composed by $90 \%$ - 98\% (weight) of triglycerides and small amounts of mono and diglycerides, free fatty acids $(1 \%-5 \%)$, and residual amounts of phospholipids, phosphatides, carotenes, tocopherols, sulphur compounds, and traces of water $[15,16]$. In particular phospholipids are known to inhibit the transesterification reaction that is central to biodiesel production [17-19], and would likely increase the types of impurities in the final product and potentially contribute to a higher viscosity. Moreover, the presence of phosphorus in bio- 
diesel is responsible for a lower efficiency and a relatively rapid deterioration of after-treatment systems to reduce exhaust emissions: for this reason biodiesel must meet stringent phosphorus specifications, with a current limit stated to $10 \mathrm{ppm}[20,21]$. Indeed low quality raw oils need a refinery step, called degumming, before being converted into biodiesel.

This refinery step is fundamental if microalgae are used as biodiesel feedstock. Indeed, while seeds oils generally comprise more than $95 \%$ triglycerides, microalgal total lipids normally include also large amount of glycoand phospholipids, chlorophylls, carotenoids and sterols. All these molecules are subdivided in two main classes, polar and nonpolar lipids, based on their chemical characteristics. 9 Nonpolar lipids include mono-, di- and triglycerides, isoprenoid-type hydrocarbons and waxes, while the polar lipids class is constituted mainly by phospholipids and glycolipids.

In this work the productivity and quality of Chlorella vulgaris lipids were evaluated in response to different growing conditions, in order to maximize the productivity of nonpolar lipids. In particular, nitrogen and phosphorus starvations were analysed in three different trophic regimens: photoautotrophy, heterotrophy and mixotrophy. C. vulgaris in fact is able to exploit both solar radiation and organic substrates to gain energy that can be largely stored in form of lipids when there is no nitrogen in the growth medium. It is already known in fact that nitrogen starvation prevents cellular duplication, triggering the intracellular carbon fluxes toward lipids synthesis. In order to promote specifically the de novo triglycerides synthesis, different kinds of phosphorus starvations were evaluated simultaneously with nitrogen starvations.

\section{Materials and Methods}

\subsection{Algal Cultures and Media}

The microalgal strain of Chlorella vulgaris used in this study was kindly provided by Prof. Torzillo G., (CNR Istituto di Ricerca sugli Ecosistemi, Sesto Fiorentino, Italy) and was cultivated under autotrophic growth conditions in BG-11 medium, consisting of $1.50 \mathrm{~g} / \mathrm{L} \mathrm{NaNO}{ }_{3}, 0.04$ $\mathrm{g} / \mathrm{L} \quad \mathrm{K}_{2} \mathrm{HPO}_{4}, \quad 75.0 \quad \mathrm{mg} / \mathrm{L} \quad \mathrm{MgSO}_{4} \cdot 7 \mathrm{H}_{2} \mathrm{O}, 36.0 \mathrm{mg} / \mathrm{L}$ $\mathrm{CaCl}_{2} \cdot 2 \mathrm{H}_{2} \mathrm{O}, 6.0 \mathrm{mg} / \mathrm{L}$ citric acid, $6.0 \mathrm{mg} / \mathrm{L} \mathrm{Fe}$ ammonium citrate, $20.0 \mathrm{mg} / \mathrm{L} \mathrm{Na} \mathrm{CO}_{3} 1.0 \mathrm{mg} / \mathrm{L} \mathrm{Na}-\mathrm{EDTA}$, $2.86 \mathrm{mg} / \mathrm{L} \mathrm{H}_{3} \mathrm{BO}_{3}, 1.81 \mathrm{mg} / \mathrm{L} \mathrm{MnCl}_{2} \bullet 4 \mathrm{H}_{2} \mathrm{O}, 0.22 \mathrm{mg} / \mathrm{L}$ $\mathrm{ZnSO}_{4} \cdot 7 \mathrm{H}_{2} \mathrm{O}, 0.39 \mathrm{mg} / \mathrm{L} \quad \mathrm{Na}_{2} \mathrm{MoO}_{4} \cdot 2 \mathrm{H}_{2} \mathrm{O}, 79.0 \mu \mathrm{g} / \mathrm{L}$ $\mathrm{CuSO}_{4} \cdot 5 \mathrm{H}_{2} \mathrm{O}, 49.4 \mu \mathrm{g} / \mathrm{L} \mathrm{Co}\left(\mathrm{NO}_{3}\right)_{2} \cdot 6 \mathrm{H}_{2} \mathrm{O}$. Before the late-exponential growth phase, the cells were used as inocula for the start-up of the experimental autotrophic, mixotrophic and heterotrophic cultures in the way to always obtain the same initial cellular density.

All cultures were performed in $6 \mathrm{~cm}$ diameter $500 \mathrm{~mL}$ glass tubes bubbled with air (flow rate of $600 \mathrm{~mL} / \mathrm{min}$ ), maintained at $25^{\circ} \mathrm{C} \pm 1{ }^{\circ} \mathrm{C}$ and exposed to a light intensity of $216 \mu \mathrm{mol}$ photons $\mathrm{m}^{-2} \cdot \mathrm{s}^{-1}$ provided by daylight fluorescent tubes, with a L/D photoperiod of 12:12 h. All the experimentations lasted $72 \mathrm{~h}$ and were performed in triplicates.

For mixotrophic cultures, glucose was added to the culture broth in concentration of $6 \mathrm{~g} / \mathrm{L}$ maintaining the same L/D photoperiod of 12:12 h. Analogously, the condition of heterotrophy was induced by adding glucose to the medium in concentration of $6 \mathrm{~g} / \mathrm{L}$ and then maintaining the cultures in complete dark.

All the starvation media were created from BG-11, modified to obtain the chosen nutrients starvation conditions: nitrogen limitation $\left(\mathrm{N}_{\mathrm{lim}}\right)$, nitrogen deprivation $\left(\mathrm{N}_{\mathrm{dep}}\right)$, simultaneous nitrogen limitation and phosphorus limitation $\left(\mathrm{N}_{\mathrm{lim}} \mathrm{P}_{\text {lim }}\right)$, simultaneous nitrogen limitation and phosphorus deprivation $\left(\mathrm{N}_{\text {lim }} \mathrm{P}_{\text {dep }}\right)$.

Nitrogen and phosphorus depleted conditions were obtained by excluding in the composition of BG-11 medium the considered element (respectively in the form of $\mathrm{NaNO}_{3}$ and $\mathrm{K}_{2} \mathrm{HPO}_{4}$ ). Limiting conditions were obtained using depleted BG-11 medium and adding twice daily the depleted element in controlled amounts. In the case of nitrogen starvation, an amount of $\mathrm{NaNO}_{3}$ equal to $1 / 16$ of the daily requirement was added twice daily to the $\mathrm{NaNO}_{3}$-free medium

The nitrogen need was previously estimated by anionic chromatography (DIONEX-120, IonPac AS12A anionic column with SRS, using as eluant a solution of $2.7 \mathrm{mM} \mathrm{Na}_{2} \mathrm{CO}_{3}$ and $0.3 \mathrm{mM} \mathrm{NaHCO}_{3}$ with a flow of 1.5 $\mathrm{ml} / \mathrm{min}$ at temperature). The mean nitrogen daily requirement during $72 \mathrm{~h}$ batch cultures ran in the same conditions and at the same initial cellular concentration used in autotrophic regimen in complete BG-11 medium was equal to $0.4 \mathrm{~g} / \mathrm{Ld}$.

Limiting conditions for phosphorus were imposed following the same procedure, with daily additions of $\mathrm{K}_{2} \mathrm{HPO}_{4}$ equal to $1.3 \mathrm{mg} / \mathrm{L}$, calculated from the nitrogen limiting conditions and maintaining the same BG-11 N/P molar ratio. The chosen limiting phosphorus concentration is below the minimum one required for Chlorellasp [22].

\subsection{Algal Growth and Cellular Density}

For autotrophical cultures, algal growth was determined by measuring routinely the optical density (OD) at 686 $\mathrm{nm}$ by a Sequoia-Turner 340 spectrophotometer and correlating it to cells density, measured by cellular count in Burker chamber $(\mathrm{CD}$, cells * $107 / \mathrm{mL})$, by the linear relationships:

$$
C D=3.8717 * O D_{686} R^{2}=0.962
$$


previously determined for this strain.

For mixotrophical and heterotrophical cultures, OD as a measure of algal growth may be misleading due to the depletion of pigments correlated with these trophicregimens [23-25]. Thus in these conditions algal growth and cellular density were estimated directly by cell count in Burker chamber (CD, cells $/ \mathrm{mL}$ ).

For the determination of biomass production at the end of each experimentation the algal biomass was harvested and recovered from the medium by centrifugation $(4500$ $\mathrm{rpm}, 10 \mathrm{~min}$ ), then dried at $105^{\circ} \mathrm{C}$ for $12 \mathrm{~h}$ and weighted. The dried biomass was stored at $-20^{\circ} \mathrm{C}$ for the subsequent lipids analysis.

\subsection{Glucose Concentration}

The glucose uptake by the different cultures was determined measuring the residual glucose concentration by means of the dinitrosalicyliccolorimetric method. This method evaluates the presence of free carbonyl group $(\mathrm{C}=\mathrm{O})$, the so-called reducing sugars. This involves the oxidation of the functional group of aldehydes and ketonespresent, for example, in glucose and fructose respectively. This method is based on the reduction of 3,5dinitrosalicylic acid (DNS) to 3-amino,5-nitrosalicylic acid, an aromatic compound that absorbs light strongly at $575 \mathrm{~nm}$, under alkaline conditions. This colour tests were made with $3 \mathrm{~mL}$ aliquots of modified Suniner and Sisler reagent added to $3 \mathrm{~mL}$ aliquots of glucose solution in 14 $\mathrm{mm}$ tubes. The mixtures were heated for 5 minutes in a boiling water bath and then cooled under running tap water to ambient temperature. Cooling to ambient temperature was made necessary by the effect of temperature on the absorbance of the coloured reaction product. The colourintensities were measured at $575 \mathrm{~nm}$. A modified reagent of Suniner and Sisler was used in the tests, composed by $1 \%$ dinitrosalicylic acid, $0.2 \%$ phenol, $0.05 \%$ sodium sulfite, and $1 \%$ sodiumhydroxide. To stabilize the reaction colour $1 \mathrm{~mL}$ of a $40 \%$ solution of Rochellesalt was added to the mixture of reactants subsequent to the development of the colour and prior to cooling.

\subsection{Lipids Content}

Lipids were soxhletextracted under inertatmosphere from dried, mortar-pulverized algal biomass samples with dichloromethane/methanol [26]. Total lipids were determined gravimetrically by evaporating the solvents under vacuum and drying the extract for $4 \mathrm{~h}$ at $80^{\circ} \mathrm{C}$.

For the determination of lipids classes, the crude lipids dried sample $(\sim 50 \mathrm{mg})$ was then resuspend end in $30 \mathrm{~mL}$ hexane with $0.1 \mathrm{ml}$ of distilled water added to favor the swelling of polar lipids, carefully shaken ( $5 \mathrm{~min}$ by a vortex mixer), ultrasonicated (30 $\mathrm{min})$ and finally centrifug- ed (4500 rpm, $5 \mathrm{~min}$ ). The supernatant solution was withdrawn and on the heavy phase the procedure was repeated two more times to ensure the complete nonpolar lipids extraction. All the withdrawn hexane solutions were mixed, evaporated under vacuum, dried for $4 \mathrm{~h}$ at $80^{\circ} \mathrm{C}$. The amount of nonpolar lipids were determined gravimetrically. Similarly, after centrifugation, the heavy phase was dried for $4 \mathrm{~h}$ at $80^{\circ} \mathrm{C}$ and weighed aspolar lipids. The determination of lipids classes was performed in duplicate for each sample and the obtained results were validated using solid-phase extraction (SPE) method ology $[27,28]$. The agreement between the values obtained with the two methods was good. The accordance of the performed method to determine lipid classes with the SPE method was within $\pm 2 \%$.

\subsection{Kinetics and Yieldparameters}

The lipids content $L(\%)$ was calculated by the equation:

$$
L(\%)=\frac{W_{L}}{W_{B}}
$$

where $W_{L}$ and $W_{B}$ are the weights of the extracted lipids and of the dry biomass, respectively.

The biomass productivity $P_{B}(\mathrm{mg} / \mathrm{Ld})$ was calculated by the equation:

$$
P_{B}=\frac{\left(W_{B F}-W_{B 0}\right)}{t}
$$

where $W_{B 0}$ and $W_{B F}$ are the weights of dry biomass at the begin and the end of a batch run and $t$ is the overall culture time.

The lipid productivity $P_{L}(\mathrm{mg} / \mathrm{Ld})$ was calculated as the product of biomass productivity and lipid content according to the following equation:

$$
P_{L}=P_{B} * L(\%)
$$

\section{Results and Discussion}

In this work, the effects of nitrogen and phosphorus starvation in three trophic regimens (photoautotrophic, heterotrophic and mixotrophic) were systematically investigated on C. vulgaris, regarding the algal growth, the biomass productivity, the lipid content, productivity and quality, with the aim of enhancing productivity of nonpolar lipids suitable for biodiesel production.

Preliminary experimental cultures, performed in autotrophic regimen in complete BG-11 medium, allow to individuate the optimal growth phase for harvesting the microalgal biomass. A harvesting time of $72 \mathrm{~h}$ after inocula was adequate to reach the late exponential growth phase, corresponding to the maximal lipid productivities $[23,29]$. This harvesting time was applied in all the tro- 
phic regimens and for the different starved growing conditions.

A period of $72 \mathrm{~h}$ appears also reasonable as industrial pre-harvesting cultural step to maximize the nonpolar lipids yield of the crop.

\subsection{Autotrophic Starvation}

The first set of starvation tests were conducted in autotrophic regimen and the growth curves are reported in Figure 1.

As reasonably expected, the complete BG-11 growth medium allows the highest cellular duplication rate, while the complete absence of nitrogen in the cultural broth $\left(\mathrm{N}_{\mathrm{dep}}\right)$ strongly inhibits C. vulgaris propagation. The merely nitrogen limitation $\left(\mathrm{N}_{\mathrm{lim}}\right)$ results in a growth rate closed to the one obtained in complete growth medium. The two co-starvations of nitrogen and phosphor $\left(\mathrm{N}_{\text {lim }} \mathrm{P}_{\text {dep }}\right.$ and $\left.\mathrm{N}_{\text {lim }} \mathrm{P}_{\text {lim }}\right)$ instead are particularly harsh, limiting the $\mathrm{C}$. vulgaris growth rate to levels just above that observed in nitrogen absence $\left(\mathrm{N}_{\mathrm{dep}}\right)$. This is probably due to the detrimental effect of phosphor starvation on photosynthesis. Phosphorus is present in phosphorus-rich ribosomes where photosynthetic linked proteins are synthesized [30]. Therefore limiting phosphate availability may reduce photosynthetic activity resulting in a lowered growth rate [31]. In addiction it is required for ATP synthesis, though there has been evidence showing that only at severe deficiencies ATP levels are affected substantially [32].

In Figure 2 the weight and the lipid content of each growing condition are reported.

It can be seen that biomass production reflects largely the growth rate previously described. However the lipids content, measured in each nutrient starved condition respect to the complete growth medium, does not reflect the difference between the various biomass productions.

\subsection{Heterotrophic Starvation}

The second trophic regimen exploited for nutrient starvation was heterotrophy. As shown by the growth curves reported in Figure 3, a higher growth rate than that

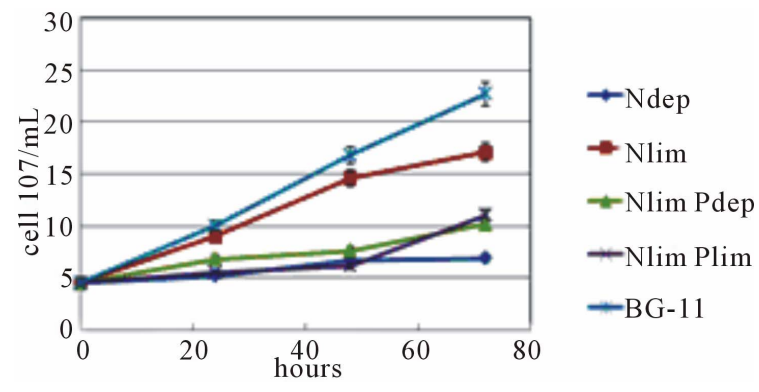

Figure 1. C. vulgaris autotrophic growth curve.

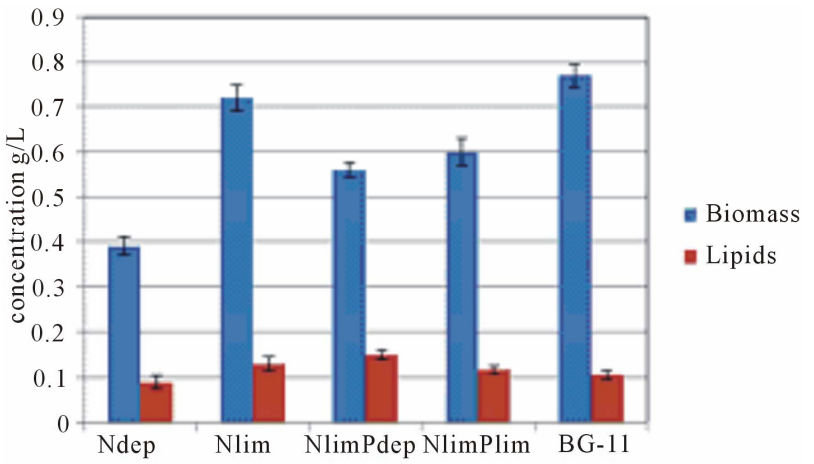

Figure 2. Biomass and lipids production during autotrophic starvation.

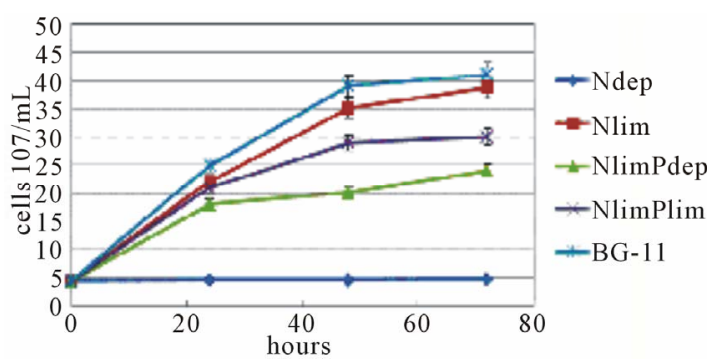

Figure 3. C. vulgaris heterotrophic growth curve.

observed in autotrophy was measured in all the tested growing conditions. BG-11 and $\mathrm{N}_{\text {lim }}$ media allow the highest growth rate, while $\mathrm{N}_{\text {dep }}$ is incompatible with cellular duplication. In comparison with autotrophic regimen, there are no significant differences between BG-11 and $\mathrm{N}_{\text {lim }}$ medium. This can be accounted to the absence of the solar radiation that limits the $C$. Vulgaris growth in complete medium. Light, indeed, is not only the energetic source of photosynthesis but represents a physiological stimulus for the cellular duplication [33].

Unexpectedly, nitrogen and phosphor starvations were more tolerable resulting in a fair growth rate. This evidence supports the hypothesis of a limiting effect of phosphorus starvation on photosynthesis rate [31]. The presence of glucose in the growth media allows $C$. vulgaris to exploit heterotrophic energetic metabolisms, instead of photosynthesis, supporting the requirements for cellular duplication.

The measurements of glucose uptake support this assumption. As reported in Figure 4, in fact, the $\mathrm{N}_{\text {lim }} \mathrm{P}_{\text {lim }}$ and $\mathrm{N}_{\text {lim }} \mathrm{P}_{\text {dep }}$ growing conditions are those in which $C$. vulgaris consumes the largest amount of glucose.

In Figure 5 the weight and the lipid content of each growing condition are reported.

The presence of an oxidizable carbon substrate in the growth medium leads to a considerable increase in biomass and lipid production for all the tested starvations. In heterotrophic regimen $\mathrm{N}_{\text {lim }} \mathrm{P}_{\text {lim }}$ and $\mathrm{N}_{\text {lim }} \mathrm{P}_{\text {dep }}$ biomass productivities are closed to that observed in $\mathrm{N}_{\mathrm{dep}}$. Also 


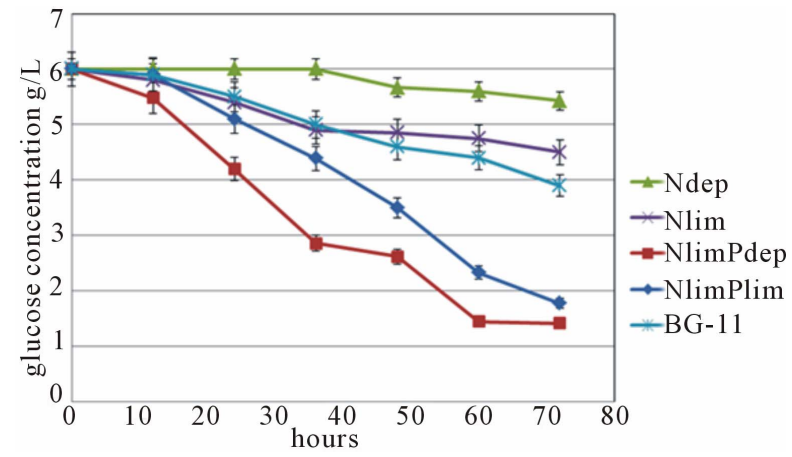

Figure 4. C. vulgaris cultural broth glucose concentration in heterotrophic conditions.

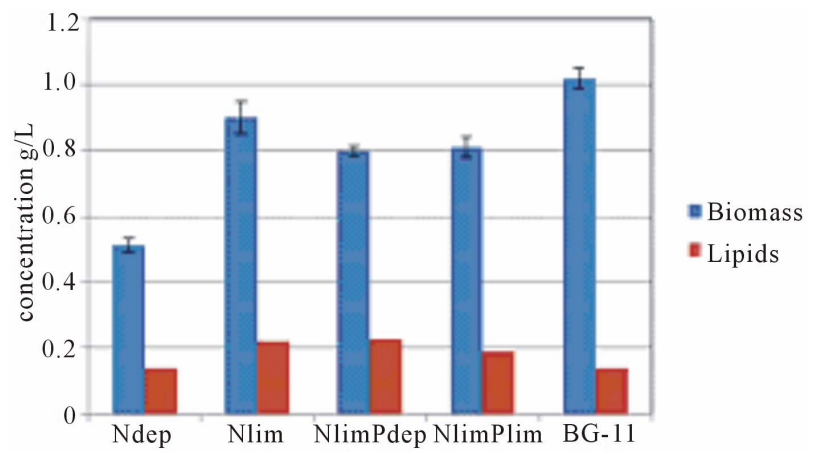

Figure 5. Heterotrophic biomass and lipids production.

lipids content increases in comparison with autotrophic conditions.

\subsection{Mixotrophic Starvation}

The last trophic regimen exploited for nutrient starvation was mixotrophy and the relative growth curves are reported in Figure 6. In this condition the presence of an oxidizable organic substrate in the growth medium allows the cultures to reach the highest cellular concentration measured.

The best results were obtained in BG-11 medium where the value of the cellular concentration was superior to $8 \times$ $108 \mathrm{cell} / \mathrm{mL}$. This value shows the capability of $C$. vulgaris to exploit autotrophic and heterotrophic metabolisms either without a preference. Moreover the higher cellular density and glucose consumption in comparison with BG-11 heterotrophic cultures confirm the promoting effect of the solar radiation on microalgae cellular duplication. Unlike in heterotrophy, $\mathrm{N}_{\text {lim }}$ culture reached $6 \times$ $108 \mathrm{cell} / \mathrm{mL}$, confirming that in presence of the light stimulus to cellular duplication, nitrogen starvation restricts culture propagation. This is also supported by the lower glucose consumption measured for $\mathrm{N}_{\lim }$ mixotrophic cultures, in comparison with that measured for the $\mathrm{N}_{\text {lim }}$ heterotrophic cultures (Figure 7).

$\mathrm{N}_{\text {lim }} \mathrm{P}_{\text {lim }}$ and $\mathrm{N}_{\text {lim }} \mathrm{P}_{\text {dep }}$ growth curves showed no differ-

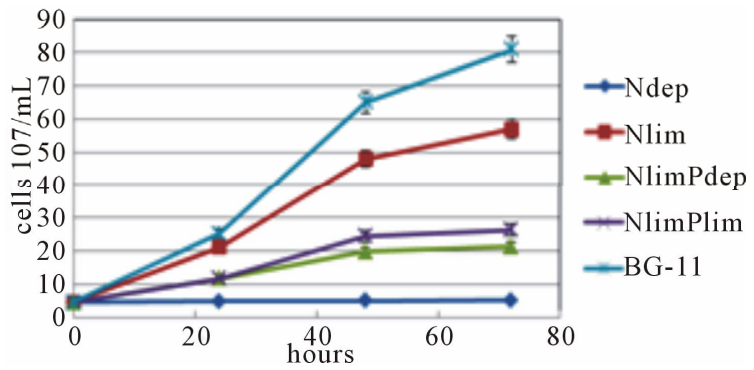

Figure 6. C. vulgarismixotrophic growth curves.

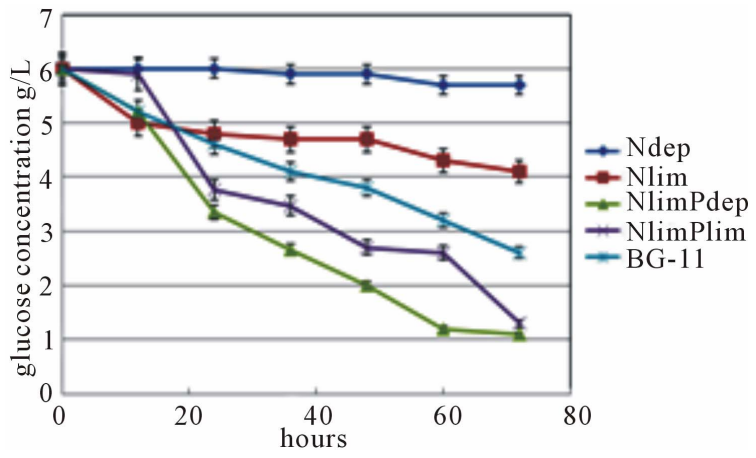

Figure 7. C. vulgaris cultural broth glucose concentration in mixotrophic conditions.

ences in comparison with those measured in heterotrophic condition. This evidence confirms that phosphor starvation switch off the photosynthetic machinery, as previously supposed. For these cultures in fact the glucose consumption in mixotrophy is analogous to that in heterotrophy.

In Figure 8 the biomass and lipid concentrations content of each growing condition are reported. According to the growth curves measured, also the biomass productions were the highest. The trend is similar to the one observed for heterotrophy. Particularly interesting is the lipid production reached in the $\mathrm{N}_{\text {lim }} \mathrm{P}_{\text {dep }}$ starvation condition where the lipid content of the biomass was the $40 \%$.

\subsection{Effect of Starvations and Trophic Regimens on Lipids Quality and Productivity}

As already mentioned increasing the lipids productivity is a crucial requirement for the feasibility of microalgae as biodiesel feedstock and in particular starving media can lead to a relevant increase in $C$. vulgaris lipids content as can be seen in Figure 9.

In all the growing conditions tested, in fact, starvations channeled the carbon fluxes inside $C$. vulgaris towards the lipids accumulation, while the complete BG-11 medium always results in high biomass production but with low lipids content. The highest lipid contents were induced by the $\mathrm{N}_{\text {lim }} \mathrm{P}_{\text {dep }}$ medium in all the trophic regimens. In this condition in fact, the nitrogen and phosphorus 


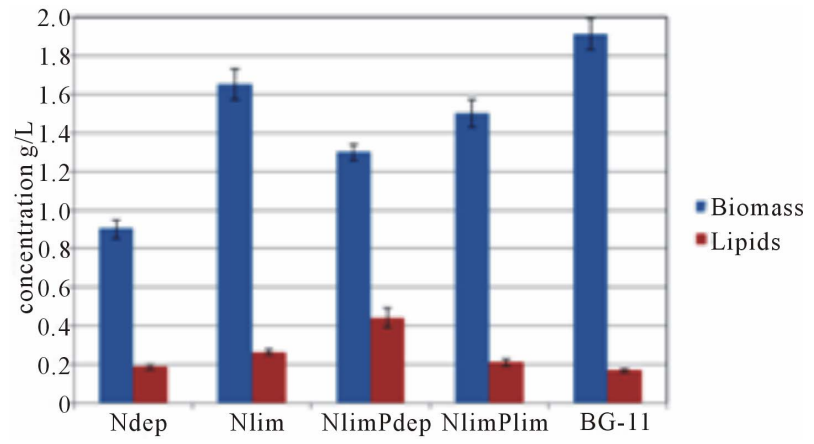

Figure 8. Mixotrophic biomass and lipids production.

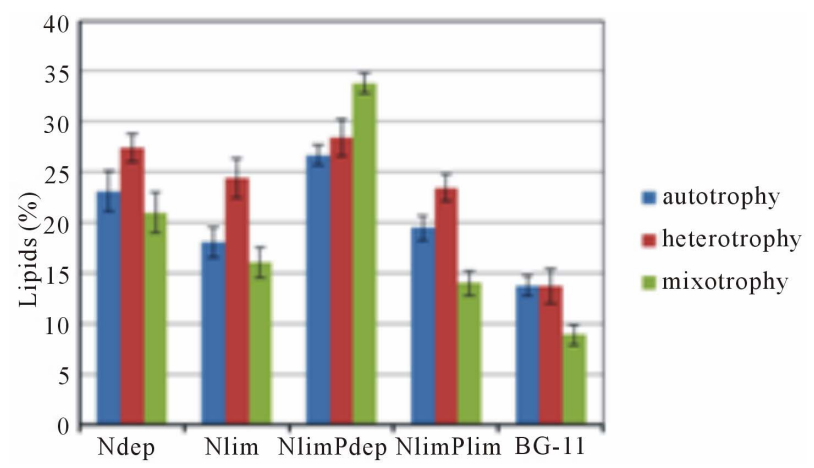

Figure 9. C. vulgaris lipids content in all the growing conditions tested.

starvations divert the inorganic carbon fixation from DNA and proteins synthesis toward lipids synthesis. This synergic effect can be explained because although nitrogen is considered the single most critical nutrient to channel metabolic flux to lipid biosynthesis, even phosphorus is known to affect lipids metabolism in algae. The absence of phosphor in the cultural medium in fact causes the photosynthesis repression. In this way the photosynthesis derived precursors of starch cannot be synthetized and the energetic surplus induced by the limitation of cellular duplication is largely stored in form of lipids.

Regarding the trophic regimens it can be noted how heterotrophy is always preferable to autotrophy in order to induce lipids synthesis in microalgae. The only exception was observed in mixotrophy for $\mathrm{N}_{\text {lim }} \mathrm{P}_{\text {dep }}$ medium in which the more efficient lipids inducing starvation and the high biomass productivity, due to synergy of autotrophic and heterotrophic metabolisms, lead to the highest lipids productivity of the experimentations (Table 1).

Nevertheless restricting the evaluation of effectiveness of nitrogen starvations to total lipids productivity may be misleading. For this reason the total lipids recovered from the tested growing conditions were divided into the polar and nonpolar fractions and the results are reported in Figure 10.

As it can be seen, these results change the above con-

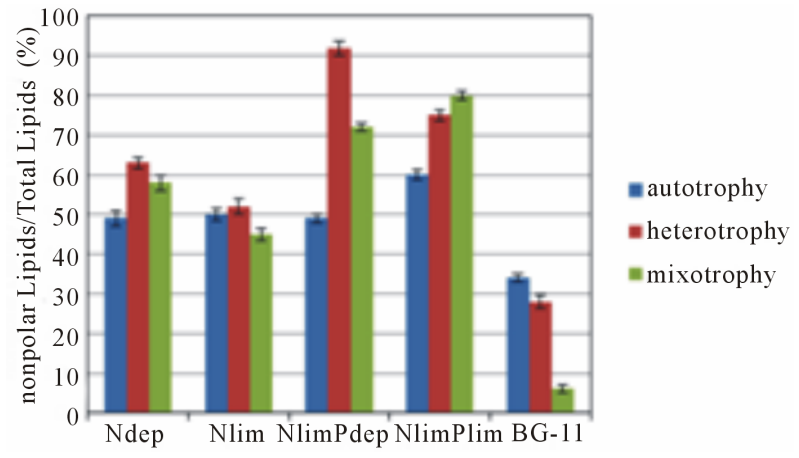

Figure 10. C. vulgaris nonpolar lipid fraction in all the growing conditions teste.

siderations. Mixotrophy results more convenient than autotrophy. On the contrary heterotrophy is less favorable than what observed previously. However $\mathrm{N}_{\text {lim }} \mathrm{P}_{\text {dep }}$, and in general phosphor starvation, is to be considered as the best condition for the induction of nonpolar lipids synthesis. In the case of autotrophy and mixotrophy the phosphorus limitation leads to a major production of polar lipids. In fact, besides nucleic acids, there are alternative nonphosphorus membrane lipid molecules that may be substituted for phospholipids. These substitute lipids have the same ionic charge as phospholipids, and thus serve similar biochemical purposes within cells [33].

Considering the nonpolar lipids content and biomass productivity, the nonpolar lipids productivity was calculated and reported in Table 1. This parameter is one of the most important for the selection of the most appropriate microalgae strain for biodiesel production. Oleaginous biomass, in fact, are often characterized by low growth rate, especially if grown in starved conditions to maximize the nonpolar lipids content. For this reason is essential to optimize the growing conditions to ensure high nonpolar lipid content and fair biomass production, ie high nonpolar lipids productivity. As it can be seen from Table 1 the highest nonpolar lipids productivity is reached for mixotrophic $\mathrm{N}_{\text {lim }} \mathrm{P}_{\text {dep }}$ cultures. Even if phosphorus is an obligate requirement for the growth of all organisms, in fact, microalgae have the ability to lower their physiological phosphorus demand by as much as $50 \%$ in response to phosphorus limitation. The physiological mechanisms for support cellular duplication, while the overall phosphorus availability is lowered, are to reducing either nucleic acids or phospholipids synthesis rates [34]. In this way the better balancing between biomass productivity and nonpolar lipids content leads to the higher nonpolar lipids productivity.

\section{Conclusions}

The selection of microalgae strains as biodiesel feedstock should be based on their nonpolar lipids productivity. 
Table 1. Effect of starvations and trophic regimens on $C$. vulgaris biomass, total lipids and nonpolar lipids productivities.

\begin{tabular}{|c|c|c|c|c|c|c|c|c|c|c|c|c|}
\hline \multicolumn{13}{|c|}{ Productivity (g /Ld) } \\
\hline & \multicolumn{4}{|c|}{ Autotrophy } & \multicolumn{4}{|c|}{ Mixotrophy } & \multicolumn{4}{|c|}{ Heterotrophy } \\
\hline & $\mathrm{P}_{\mathrm{B}}$ & $\mathrm{P}_{\mathrm{TL}}$ & $\mathrm{P}_{\mathrm{NPL}}$ & $\mathrm{P}_{\mathrm{NPL}} / \mathrm{P}_{\mathrm{TL}} \%$ & $\mathrm{P}_{\mathrm{B}}$ & $\mathrm{P}_{\mathrm{TL}}$ & $\mathrm{P}_{\mathrm{NPL}}$ & $\mathrm{P}_{\mathrm{NPL}} / \mathrm{P}_{\mathrm{TL}} \%$ & $\mathrm{P}_{\mathrm{B}}$ & $\mathrm{P}_{\mathrm{TL}}$ & $\mathrm{P}_{\mathrm{NPL}}$ & $\mathrm{P}_{\mathrm{NPL}} / \mathrm{P}_{\mathrm{TL}} \%$ \\
\hline BG-11 & 0.181 & 0.024 & 0.008 & 34 & 0.561 & 0.046 & 0.002 & 6 & 0.265 & 0.036 & 0.010 & 28 \\
\hline $\mathrm{N}_{\lim }$ & 0.165 & 0.032 & 0.009 & 50 & 0.475 & 0.075 & 0.034 & 45 & 0.225 & 0.062 & 0.032 & 52 \\
\hline $\mathrm{N}_{\text {dep }}$ & 0.055 & 0.019 & 0.016 & 49 & 0.225 & 0.052 & 0.030 & 58 & 0.095 & 0.036 & 0.022 & 63 \\
\hline $\mathrm{N}_{\lim } \mathrm{P}_{\lim }$ & 0.125 & 0.028 & 0.017 & 60 & 0.425 & 0.059 & 0.047 & 80 & 0.195 & 0.052 & 0.039 & 75 \\
\hline $\mathrm{N}_{\text {lim }} \mathrm{P}_{\text {dep }}$ & 0.111 & 0.039 & 0.019 & 49 & 0.358 & 0.135 & 0.097 & 72 & 0.191 & 0.065 & 0.060 & 92 \\
\hline
\end{tabular}

$\mathrm{P}_{\mathrm{B}}$ : biomass productivity; $\mathrm{P}_{\mathrm{TL}}$ : total lipids productivity; $\mathrm{P}_{\mathrm{NPL}}$ : nonpolar lipids productivity; $\mathrm{P}_{\mathrm{NPL}} / \mathrm{P}_{\mathrm{TL}}$ : percentage productivity of nonpolar lipids on total lipids productivity.

This parameter is the result of the interaction between the genetic characteristics of the algal strain and the growing conditions. In this paper nitrogen and phosphorus starvations were exploited specifically for nonpolar lipids production by Chlorella vulgaris during autotrophy, heterotrophy and mixotrophy.

Nitrogen starvations were found to represent only a slight improvement for lipids productivity. By means of nitrogen and phosphorus co-starvation it was possible to increase total lipids productivity and to switch the lipid composition in favour of nonpolar lipids in all the trophic regimes tested. Maximum nonpolar lipids productivity was obtained in nitrogen limited and phosphorus deprived condition during mixotrophic growth. In this condition in fact nitrogen and phosphorus co-starvation together with glucose and solar radiation leads to the highest nonpolar lipids content, without breaking down the biomass production therefore resulting in the highest nonpolar lipids productivity.

The obtained results suggest that a two-stage culture strategy can be an option for enhancing lipid productivity. In the first stage, the algae are cultured in nutrient-sufficient conditions to obtain a maximized cell density as quickly as possible and, in the second pre-harvesting cultural stage, the growing conditions are modulated to trigger the accumulation of lipids.

\section{REFERENCES}

[1] L. Brennan and P. Owende, "Biofuels from Microalgae -A Review of Technologies for Production, Processing, and Extractions of Biofuels and Co-Products," Renewable and Sustainable Energy Reviews, Vol. 14, No. 2, 2010, pp. 557-577. http://dx.doi.org/10.1016/j.rser.2009.10.009

[2] E. Suali and R. Sarbatly, "Conversion of Microalgae to Biofuel," Renewable and Sustainable Energy Reviews, Vol. 16, No. 6, 2012, pp. 4316-4342. http://dx.doi.org/10.1016/j.rser.2012.03.047

[3] Y. Chisti, "Biodiesel from Microalgae," Biotechnology
Advances, Vol. 25, No. 3, 2007, pp. 294-306. http://dx.doi.org/10.1016/j.biotechadv.2007.02.001

[4] Q. Hu, M. Sommerfeld, E. Jarvis, M. Ghirardi, M. Posewitz, M. Seibert and A. Darzins, "Microalgaltriacylglycerols as Feedstocks for Biofuel Production: Perspectives and Advances," The Plant Journal, Vol. 54 No. 4, 2008, pp. 621-639.

http://dx.doi.org/10.1111/j.1365-313X.2008.03492.x

[5] P. M. Schenk, S. R. Thomas-Hall, E. Stephens, U. C. Marx, J. H. Mussgnug, C. Posten, O. Kruse and B. Hankamer, "Second Generation Biofuels: High-Efficiency Microalgae for Biodiesel Production," Bioenergy Research, Vol. 1, No. 1, 2008, pp. 20-43. http://dx.doi.org/10.1007/s12155-008-9008-8

[6] F. B. Metting, "Biodiversity and Application of Microalgae," Journal of Industrial Microbiology \& Biotechnology, Vol. 17, No. 5-6, 1996, pp. 477-489. http://dx.doi.org/10.1007/BF01574779

[7] P. Spolaore, C. Joannis-Cassan, E. Duran and A. Isambert, "Commercial Applications of Microalgae," Journal of Bioscience and Bioengineering, Vol. 101, No. 2, 2006, pp. 87-96. http://dx.doi.org/10.1263/jbb.101.87

[8] L. Rodolfi, G. C. Zittelli, N. Bassi, G. Padovani, N. Biondi, G. Bonini and M. R. Tredici, "Microalgae for Oil: Strain Selection. Induction of Lipid Synthesis and Outdoor Mass Cultivation in a Low-Cost Photobioreactor," Biotechnol and Bioengineering, Vol. 102, No. 1, 2009, pp. 100-112. http://dx.doi.org/10.1002/bit.22033

[9] G. C. Dismukes, D. Carrieri, N. Bennette, G. M. Ananyev and M. C. Posewitz, "Aquatic Phototrophs: Efficient Alternatives to Land-Based Crops for Biofuels," Current Opinion in Biotechnology, Vol. 19, No. 3, 2008, pp. 235240. http://dx.doi.org/10.1016/j.copbio.2008.05.007

[10] X. Li, H.-Y. Hu, K. Gan and Y.-X. Sun, "Effects of Different Nitrogen and Phosphorus Concentrations on the Growth, Nutrient Uptake, and Lipid Accumulation of a Freshwater Microalga Scenedesmus sp.," Bioresource Technology, Vol. 101, No. 14, 2010, pp. 5494-5500. http://dx.doi.org/10.1016/j.biortech.2010.02.016

[11] P. E. Zemke, B. D. Wood and D. J. Dye, "Considerations for Maximum Production Rates of Triacylglycerol from 
Microalgae," Biomass and Bioenergy, Vol. 34, No. 1, 2010, pp. 145-151.

http://dx.doi.org/10.1016/j.biombioe.2009.10.012

[12] R. Praveenkumar, K. Shameera, G. Mahalakshmi, M. A. Akbarsha and N. Thajuddin, "Influence of Nutrient Deprivations on Lipid Accumulation in a Dominant Indigenous Microalga Chlorella sp., BUM11008: Evaluation for Biodiesel Production," Biomass and Bioenergy, Vol. 37, 2012, pp. 60-66.

http://dx.doi.org/10.1016/i.biombioe.2011.12.035

[13] A. Widjaja, C. Chien and Y. Ju, "Study of Increasing Lipid Production from Fresh Water Microalgae Chlorella Vulgaris," Journal of the Taiwan Institute of Chemical Engineers, Vol. 40, No. 1, 2009, pp. 13-20. http://dx.doi.org/10.1016/j.jtice.2008.07.007

[14] G. Mujtaba, W. Choi, C. G. Lee and K. Lee, "Lipid Production by Chlorella Vulgaris after a Shift from NutrientRich to Nitrogen Starvation Conditions," Bioresource Technology, Vol. 123, 2012, pp. 279-283. http://dx.doi.org/10.1016/j.biortech.2012.07.057

[15] W. W. Christie, "Lipid Analysis," The Oily Press. PJ Barnes and Associates, Bridgewater, 2003.

[16] K. Bozbas, "Biodiesel as an Alternative Motor Fuel: Production and Policies in the European Union," Renewable \& Sustainable Energy Reviews, Vol. 12, No. 2, 2008, pp. 542-552. http://dx.doi.org/10.1016/j.rser.2005.06.001

[17] J. Van Gerpen, "Biodiesel Processing and Production," Fuel Processing Technology, Vol. 86, No. 10, 2005, pp. 1097-1017. http://dx.doi.org/10.1016/j.fuproc.2004.11.005

[18] Y. Watanabe, Y. Shimada, A. Sugihara and Y. Tominaga, "Conversion of Degummed Soybean Oil to Biodiesel Fuel with Immobilized Candida Antarctica Lipase," Journal of Molecular Catalysis B: Enzymatic, Vol. 17, No. 3-5, 2002, pp. 151-155. http://dx.doi.org/10.1016/S1381-1177(02)00022-X

[19] L. Fjerbaek, K. V. Christensen and B. Norddahl, "A Review of the Current State of Biodiesel Production Using Enzymatic Transesterification," Biotechnology and Bioengineering, Vol. 102, No. 5, 2009, pp. 1298-1315. http://dx.doi.org/10.1002/bit.22256

[20] ASTM Standard D6751 - 09a, "Standard Specification for Biodiesel Fuel Blend Stock (B100) for Middle Distillate Fuels. ASTM International," West Conshohocken, 2009. http://dx.doi.org/10.1520/D6751-09A

[21] G. Knothe, "Analyzing Biodiesel Standards and Other Methods," Journal of the American Oil Chemists' Society, Vol. 83, No. 10, 2006, pp. 823-833. http://dx.doi.org/10.1007/s11746-006-5033-y

[22] C. B. Qu, Z. Y. Wu and X. M. Shi, "Phosphate Assimilation by Chlorella and Adjustment of Phosphate Concentration in Basal Medium for Its Cultivation," Biotechnology Letters, Vol. 30, No. 10, 2008, pp. 1735-1740. http://dx.doi.org/10.1007/s10529-008-9758-6

[23] T. Heredia-Arroyo, W. Wei and B. Hu, "Oil Accumulation via Heterotrophic/Mixotrophic Chlorella Protothecoides," Applied Biochemical Biotechnology, Vol. 162, No. 7, 2010, pp. 1978-1995. http://dx.doi.org/10.1007/s12010-010-8974-4
[24] E. P. Karlander and R. W. Krauss, "Responses of Heterotrophic Cultures of Chlorella Vulgaris Beyerinck to Darkness and Light. I Pigment and $\mathrm{pH}$ Changes," Plant Physiology, Vol. 41, No. 1, 1966, pp. 1-6. http://dx.doi.org/10.1104/pp.41.1.1

[25] E. P. Karlander and R. W. Krauss, "Responses of Heterotrophic Cultures of Chlorella Vulgaris Beyerinck to Darkness and Light. II Action Spectrum for and Mechanism of the Light Requirement for Heterotrophic Growth," Plant Physiology, Vol. 41, No. 1, 1966, pp. 7-14. http://dx.doi.org/10.1104/pp.41.1.7

[26] J. B. Guckert, K. E. Cooksey and L. L. Jackson, "Lipid Solvent Systems Are Not Equivalent for Analysis of Lipid Classes in the Microeukaryotic Green Alga Chlorella," Journal of Microbiological Methods, Vol. 8, No. 6, 1989, pp. 139-149. http://dx.doi.org/10.1016/0167-7012(88)90015-2

[27] A. Lus, A. Meireles, G. Catarina and F. X. Malcata, "Lipid Class Composition of the microalga Pavlovalutheri: Eicosapentaenoic and Docosahexaenoic Acids," Journal of Agricultural and Food Chemistry, Vol. 51, No. 8, 2003, pp. 2237-2241. http://dx.doi.org/10.1021/jf025952y

[28] A. A. Carelli, M. I. V. Brevedan and G. H. Crapiste, "Quantitative Determination of Phospholipids in Sunflower Oil," Journal of the American Oil Chemists' Society, Vol. 74, No. 5, 1997, pp. 511-514. http://dx.doi.org/10.1007/s11746-997-0173-2

[29] J. M. Lu, L. H. Cheng, X. H. Xu, L. Zhang and H. L. Chen, "Enhanced Lipid Production of Chlorella Vulgaris by Adjustment of Cultivation Conditions," Bioresource Technology, Vol. 101, No. 17, 2010, pp. 6797-6804. http://dx.doi.org/10.1016/j.biortech.2010.03.120

[30] B. Wang, Y. Li, N. Wu and C. Q. Lan, "CO 2 Bio-Mitigation Using Microalgae," Appilied Biochemistry and Biotechnology, Vol. 79, No. 5, 2008, pp. 707-718. http://dx.doi.org/10.1007/s00253-008-1518-y

[31] S. White, A. Anandraj and F. Bux, "Pam Fluorometry as a Tool to Assess Microalgal Nutrient Stress and Monitor Cellular Neutral Lipids," Bioresource Technology, Vol. 102, No. 2, 2011, pp. 1675-1682. $\mathrm{http} \cdot / / \mathrm{dx}$ doi org/10.1016/i biortech 2010.09.097

[32] G. Markou, I. Angelidaki and D. Georgakakis, "Microalgal Carbohydrates: An Overview of the Factors Influencing Carbohydrates Production, and of Main Bioconversion Technologies for Production of Biofuels," Applied Microbiology and Biotechnology, Vol. 96, No. 3, 2012, pp. 631-645. http://dx.doi.org/10.1007/s00253-012-4398-0

[33] M. Moulager, A. Monnier, B. Jesson, R. Bouvet, J. Mosser, C. Schwartz, L. Garnier, F. Corellou and F. Y. Bouget, "Light-Dependent Regulation of Cell Division in Ostreococcus: Evidence for a Major Transcriptional Input," Plant Physiology, Vol. 144, No. 3, 2007, pp. 1360-1369.

[34] B. A. S. Van Mooy, H. F. Fredricks, B. E. Pedler, S. T. Dyhrman, D. M. Karl, M. Koblížek, M. W. Lomas, T. J. Mincer, L. R. Moore, T. Moutin, M. S. Rappé and E. A. Webb, "Phytoplankton in the Ocean Use Non-Phosphorus Lipids in Response to Phosphorus Scarcity," Nature, Vol. 458, 2009, pp. 69-72.

http://dx.doi.org/10.1038/nature07659 